\title{
Does the Availability of Community Health Worker/Mobile-Health Van Unit within the Community Impacts Neonatal Survival?
}

\author{
Ajay Pandey', Dilip C. Nath ${ }^{2}$, Richa Sharma ${ }^{3}$ \\ ${ }^{1}$ Population Research Centre, University of Lucknow, Uttar Pradesh, India \\ ${ }^{2}$ Department of Statistics, University of Guwahati, Assam, India \\ ${ }^{3}$ National Institute of Labour Economics Research and Development, Delhi, India \\ Email: ajaypandey.prclko@gmail.com, dilipc.nath@gmail.com, richasharmanilerd@gmail.com
}

How to cite this paper: Pandey, A., Nath, D.C. and Sharma, R. (2017) Does the Availability of Community Health Worker/Mobile-Health Van Unit within the Community Impacts Neonatal Survival? Open Journal of Statistics, 7, 803-814. https://doi.org/10.4236/ojs.2017.75057

Received: September 10, 2017

Accepted: October 22, 2017

Published: October 25, 2017

Copyright $\odot 2017$ by authors and Scientific Research Publishing Inc. This work is licensed under the Creative Commons Attribution International License (CC BY 4.0).

http://creativecommons.org/licenses/by/4.0/

\begin{abstract}
This study uses the data from the National Family Health Survey round-2. Using hierarchical linear models the role of community level variables in predicting neonatal deaths at individual level is analyzed. SAS sub-routine PROC GLIMMIX is used for hierarchical linear modeling. Findings re-enforce the importance of mother's literacy and tetanus toxid vaccination during pregnancy in predicting neonatal deaths at individual level. At community level, though the magnitude of the presence of either a private doctor, or a visiting doctor, or a village guide, or a traditional health attendant, or the presence of mobile health van unit within community is in an expected direction, the effect is statistically not significant. In order to capture true impact of community level intervention of program success it is imperative that the large demographic surveys should incorporate more and more community level indicators while designing these surveys.
\end{abstract}

\section{Keywords}

Neonatal Deaths, Mother's Literacy, Tetanus Toxid Injections

\section{Introduction}

High levels of neonatal mortality in Empowered Action Group (EAG) States in India has been well documented. The individual level determinants explaining the variations in these neonatal deaths have also been well researched. The recent stagnation in the declining trend in-spite best of governmental interventions at systemic and individual level to tackle neonatal deaths has not yielded 
much result. Community based large scale interventions in India have been extremely limited until the launch of National Rural Health Mission Programs (NRHM) in 2005. The NRHM saw tangible shift in the health policy planning not only by increased program funding and central assistance through grant-in-aid to States but also by institutionalizing the community based health workers named Accredited Social Health Activist (ASHA) per 1000 population selected from the community. Prior to the Accredited Social Health Activist (ASHA) the Auxiliary Nurse Midwives (ANM) of the sub-centre health facility were the only first level direct contacts with the community. One ANM as envisaged had a catchment of 5000 population. However currently on an average ANMs cover anything between 7000 - 12,000 population and even more depending on the catchment population growth. The importance of these community level frontline workers though always existed, it was scientifically not looked into at-least in EAG States in an Indian context. Until the launch of NRHM programs in 2005, all the new government health schemes that were launched for the betterment of the community health they got padded up on the shoulders of the ANMs. Post recruitment of ASHAs, lot of community outreach burden got shared up and the ANMs got extra time for other health sector programs including record keeping. Under the NRHM and during the $\mathrm{XI}^{\text {th }}$ five year plan realizing the importance of the community based health worker i.e. ASHA in saving new born lives in the year 2011 it was envisaged to have home based neonatal care (HBNC) to reduce the neonatal mortality. The XI ${ }^{\text {th }}$ plan [1] document states "... during the Eleventh Five Year Plan, ASHAs will be trained on identified aspects of newborn care during their training ... to supervise and provide onsite training and support to ASHAs, mentor-facilitators will be introduced for effective implementation. The national strategy during the Plan will be to introduce and make available high-quality HBNC services in all districts/areas with an infant mortality rate (IMR) more than 45 per 1000 live births. Apart from performance incentive to ASHAs, an award will be given to ASHAs and village community if no mother-newborn or child death is reported in a year."

This chapter thus focuses statistically on studying the linkages between availability of community private doctor, visiting doctor, village health guide, availability of trained attendants and mobile health units on neonatal mortality. The only available data through which one can study the impact of community level variables on individual outcome is the NFHS-2 data where village file is merged with the individual file to study the community context of individual outcome.

\section{Review}

Home based neonatal care in resource poor settings is designed considering the fact that not all deliveries occur at an institution and even if they did under the guidance of trained medical professional at an institution, majority do not prefer staying at an institution post delivery. In India and more so in demographically backward EAG States lot many women leave hospital in less than 24 hours of de- 
livery. Evidences emanating from the Health Management Information System (HMIS) data of the EAG States point towards the fact that even today lot of women leave hospital within 24 hours of normal delivery. In-spite of mandatory 48 hours stay at health facility as mandated under the Janani Sishu Suraksha Karyakram (JSSK) program under the NRHM programs launched in 2005. The 2010 study by Indian Council of Medical Research (ICMR) [2] have mapped the most vulnerable period in a newborns life which is 'at the time of birth' and during first week of life. According to the study 75 percent of all the neonatal deaths occur during first week of life and the remaining 25 percent occur between week two to four. The study also presents the distribution of neonatal deaths in first week of life with 40 percent neonatal deaths occurring on day one. Day one of the birth is when the skilled birth attendants (SBA) is needed the most. The fact is lot many ANM's in EAG States are not SBA trained. Bang et al. [3] in their community based case control intervention study in rural Gadchiroli district of Maharashtra India suggested that home-based neonatal care including management of sepsis, reduces neonatal and infant mortality by 50 percent among those mothers who are malnourished and illiterate. The study also suggested that their approach, if practiced, could reduce neonatal mortality substantially in the developing countries as well. Gogia and Sachdev [4] [5] reviewing the community based intervention study using meta analysis reported that in poor areas having limited access to facility-based health care, home visits by community health workers are associated with reduced neonatal mortality. The United States Agency for International Development (USAID) [6] report based on deliberation of the meeting held to discuss strategies for reduction of perinatal and neonatal mortality recommends three pronged approach. The three pronged approach includes intervention before delivery such as to manage reproductive tract infection/sexually transmitted infection (RTI/STI) including bacterial vaginosis, chorioamnionitis, and preterm rupture of the uterine membranes; maternal immunization with tetanus toxoid and malaria prophylaxis during routine antenatal care visits. Secondly, to manage obstetric complications by providing referral and transport services. Thirdly post delivery intervention include resuscitation of asphyxiated infants; the proper management of neonatal sepsis and other infections; skin-to-skin Kangaroo Care for preterm infants, and immediate and exclusive breastfeeding for all children. The study by Aboubaker [7] highlighted the need for adherence to treatment and follow-up by the pregnant women and community health workers need to assist the pregnant women in getting the services due. Mother and Child Tracking System (MCTS) portal of the Ministry of Health and Family Welfare (MOHFW) is an initiative in this direction by micro managing every pregnancy and reminding them of services due through portal generated due list given to the community health workers. Darmstadt [8] et al. in their study from rural Bangladesh evaluated the community health workers capacity in correctly identifying the signs and symptoms of neonatal illness during their routine household surveillance. Findings reported 
high competency levels of the community health workers in identifying the signs and symptoms of neonatal illness. The community health workers trained under integrated management of childhood illness (IMCI) were able to identify and refer neonates born at home and requiring specialized treatment. Some of these trained community health workers were so efficient that they could manage sick neonates by themselves. Under NRHM program rightly so each delivery point is equipped with New Born Care Corner (NBCC) and selected identified community health facilities have been given New Born Stabilization Units (NBSU). Besides at district level hospitals Sick Newborn Care Units (SNCU) have been provided for intensive care of the sick neonates in India. However, in a separate study by Devasenapathy et al. [9] in an Indian context while emphasizing the need delivering at an institution, reported the need for training of community health workers to strengthen their counseling skills on newborn care. In a cluster randomized case control study conducted in Vietnam Wallin et al. [10] re-iterated the importance of community health workers presence and their impact of neonatal survival even in areas that have relatively low neonatal death rates. Howe et al [11] in their study from Ghana stressed upon the need for increased training and sensitization of the community health worker's for the enhanced neonatal survival chances. Roy et al [12] in their study on eastern India advocated participatory learning and action involving community women groups in areas having high neonatal mortality. Reasons identified for reduction in neonatal mortality include better hygiene practices during delivery, including hand wash and clean cord care; improved thermal care of the neonates, and practice of exclusive breastfeeding post delivery. These interventions are not costly and largely have been incorporated into HBNC program launched in 2011 in India. Since 2012 training's have been provided to community workers i.e. ASHA in HBNC. The impact of the HBNC program needs to be captured to assess whether or not these community intervention improved the survival chances of the neonates. Kumar et al. (2009) [13] identified lack of knowledge among community and primary health care givers on neonatal hypothermia, a leading cause of high neonatal morbidity and mortality within communities. It is very recently that the Kangaroo Care rooms are made available separately at district hospitals to provide mother to baby body warmth in order to reduce morbidity and mortality due to neonatal hypothermia. Li et al. [14] in their study from rural areas of rural areas of Shaanxi Province of Northwestern China having reported all the known predictors of neonatal deaths at individual level concluded that the important determinants of neonatal mortality lie at community, health system and social level. This chapter thus focuses on the impact of the availability of community private doctors or a visiting doctors or village guide or tradition attendant and availability of mobile van on neonatal outcome. It may be argued that most of the literature on the community based intervention and its impact on neonatal deaths is after the National Family Health Survey round 2 (NFHS-2) [15] data on village indicators was collected. There is thus limitation 
in assessing the community level variables impact on individual outcome through NFHS-2 dataset. None the less it's worth analyzing scientifically whether or not, statistically, there is any impact of community level variable on neonatal deaths.

The main objectives of the study are;

- To study the clustering effect by estimation of the Intra-class correlation in order to analyze the community effect

- To study the effect of Level-1 variables (individual level) on the neonatal deaths

- To study the community presence of either the village level private doctors or the visiting doctor or the village health guide or the trained attendant or the availability of mobile health van i.e. (level-2 variables) on neonatal survival chances.

\section{Data and Methods}

Data collected from the National Family Health Survey (NFHS-2) [15] is used to investigate the presence of community level private doctor, or a visiting doctor, or village health guide, or traditional attendant or mobile health van's and its impact on the neonatal survival chances keeping other socio-economic \& demographic variables constant at individual level. The data is analyzed for the EAG states comprising of Bihar, Madhya Pradesh, Odisha, Rajasthan and Uttar Pradesh. PROC GLIMMIX in SAS is used for hierarchical linear modeling analysis.

The variables used in the analysis are as under

a) Outcome Variable: Neonatal Deaths

$0=$ Failure (Non occurrence of neonatal deaths

$1=$ Event (occurrence of neonatal deaths)

b) Independent Variables included in the model based on relative influence on outcome variable: Level-1 predictors

i) Sex of the child at the time of birth (Biological)

$0=$ Male

$1=$ Female

ii) Mothers literacy (Socio-economic-demographic)

$0=$ Illiterate

$1=$ Literate

iii) Tetanus Toxid injection during pregnancy (Government intervention) $0=$ Received no TT injection $1=$ Received any number of TT injection

c) Community (Village) level variables: Level-2 predictors

i) Availability of private doctor in the village

$0=$ No

$1=$ Yes

ii) Availability of visiting doctor in the village

$0=\mathrm{No}$ 
$1=$ Yes

iii) Availability of village health guide in the village

$0=$ No

$1=$ Yes

iv) Availability of traditional attendant in the village

$0=$ No

$1=$ Yes

v) Availability of mobile health unit

$0=$ No

$1=$ Yes

vi) Availability of either private doctor or a visiting doctor or a traditional attendant or a village health guide or a mobile health van $(h w m u)$

$0=$ No

$1=$ Yes

Findings

Table 1 presents the sample distribution of the level- 1 and level- 2 variables used in the analysis. Birth history file is used for analysis. Only those cases that belong to rural sample are used. This is done because the information at community level is available only from villages and not for the urban wards. Out of the total number of 89,455 births 6065 neonatal deaths (outcome variable) were recorded in EAG States including Bihar, Madhya Pradesh, Rajasthan, Odisha and Uttar Pradesh. At level-1 or the individual level fifty two percent of the babies were males while females were forty eight percent. Eighty percent of the mothers were illiterate while 20 percent of them were literate. Questions were asked to pregnant mothers if they received any ante natal care check-ups during pregnancy. Forty three percent of the women received any ANC services while the remaining forty seven percent of the females didn't receive any ANC services during pregnancy. Similarly sixty one percent of the pregnant women received TT injections (one or more) while 39 percent did not receive any TT injection. Ninety percent of sample population used open filed for defecation while only ten percent had toilets (flush or pit) at home. The scenario has changed in recent times since the new central government came in power in 2014 and a renewed push for providing toilets to each household across India in an effort to make India defecation free. Seventy one percent of the population was either scheduled caste or tribe or from other backward castes. Twenty nine percent belonged to the other caste category. Sixty six percent of the women had marriage to first birth interval less than or equal to 33 months while 34 percent of the women had marriage to first birth interval greater than 33 months. These 89455 births at individual level are nested in 1120 villages of the EAG States. Thirty one percent of the 1120 villages had availability of private doctors within the village. Sixty nine percent of the sampled village does not have the availability of the private doctor in the village. Twenty three percent of the villages had visiting doctors in the village while seventy seven percent does not have the facility of 
Table 1. Percentage distribution neonatal deaths and covariates at individual and village level: EAG States.

\begin{tabular}{|c|c|c|}
\hline & Observation & Proportion \\
\hline \multicolumn{3}{|c|}{ Neonatal Deaths (Dependent Variable) } \\
\hline Yes & 6065 & 6.78 \\
\hline No & 83,390 & 93.22 \\
\hline \multicolumn{3}{|c|}{ Level 1 (Individual) (Independent Variable) } \\
\hline \multicolumn{3}{|l|}{ Sex of the child } \\
\hline Male & 46,636 & 52.13 \\
\hline Female & 42,819 & 47.87 \\
\hline \multicolumn{3}{|c|}{ Mothers Literacy } \\
\hline Illiterate & 71,938 & 80.44 \\
\hline Literate & 17,494 & 19.56 \\
\hline \multicolumn{3}{|c|}{ Ante Natal checkups during pregnancy } \\
\hline Yes & 5068 & 43.05 \\
\hline No & 6704 & 56.95 \\
\hline \multicolumn{3}{|c|}{ TT injection before birth } \\
\hline Yes & 7245 & 61.29 \\
\hline No & 4576 & 38.71 \\
\hline \multicolumn{3}{|c|}{ Type of toilet facility at home } \\
\hline Open & 80,673 & 90.19 \\
\hline Flush or pit & 8776 & 9.81 \\
\hline \multicolumn{3}{|l|}{ Caste } \\
\hline$S C / S T / O B C$ & 62,193 & 70.63 \\
\hline Others & 25,862 & 29.37 \\
\hline \multicolumn{3}{|c|}{ Marriage to First Birth Interval (BI) } \\
\hline$\leq 33$ months & 15,549 & 66.32 \\
\hline$>33$ months & 7895 & 33.68 \\
\hline \multicolumn{3}{|c|}{ Level $2($ Village $=1120)($ Independent variable $)$} \\
\hline \multicolumn{3}{|c|}{ Availability of private doctor in the village } \\
\hline Yes & 343 & 30.7 \\
\hline No & 775 & 69.3 \\
\hline \multicolumn{3}{|c|}{ A vailability of visiting doctor in the village } \\
\hline Yes & 252 & 22.6 \\
\hline No & 865 & 77.4 \\
\hline \multicolumn{3}{|c|}{ Availability of village health guide in the village } \\
\hline Yes & 351 & 31.4 \\
\hline No & 766 & 68.6 \\
\hline
\end{tabular}




\section{Continued}

Availability of traditional attendant in the village

$\begin{array}{lll}\text { Yes } & 545 & 48.8 \\ \text { No } & 572 & 51.2\end{array}$

Availability of mobile health unit in the village

$\begin{array}{ccc}\text { Yes } & 92 & 8.24 \\ \text { No } & 1024 & 91.76\end{array}$

Combined Variable at Level 2 (Villages $=1111)$

Availability of doctor or attendant or mobile health unit in the village ( $h w m u$ )

$\begin{array}{lll}\text { Yes } & 812 & 73.09\end{array}$

$\begin{array}{lll}\text { No } & 299 & 26.91\end{array}$

visiting doctors in the village. Thirty one percent of the villages had the facility of village health guide while the remaining sixty nine percent does not have village health guide. Forty nine percent of the villages had the facility of traditional attendant while the remaining 51 percent of the village does not have any traditional attendant. Eight percent of the villages had mobile health unit in the village while the remaining ninety two percent does not have the facility of mobile health unit in the village. Based on these five village level variable a combined variable was created. Villages that have private doctor, visiting doctor, traditional attendant, village health guide or mobile health unit was coded as 1 and rest as zero. Seventy three percent of the villages had either private doctor, visiting doctor, traditional attendant, village health guide or mobile health unit while twenty seven percent had none. This constructed variable was used to study the village level effect on neonatal survival.

Table 2 provides the intra-class correlation (ICC) under GLIMIX procedure based on unconstrained model. The unconstrained model does not include any predictor variable and the estimates of random intercept provide the ICC value based on the following model specification (1). In the Equation (1) $\eta_{i j}$ is the $\mathrm{i}^{\text {th }}$ neonatal death in the $\mathrm{j}^{\text {th }}$ community. $\beta_{0 j}$, is the intercept effect of the jth community. $\gamma_{00}$, is the overall intercept effect and the $\mu_{0 j}$, is the variance of the jth community. The $\mathrm{j}$ subscript tells us that a different Level-1 model is being estimated for each of the $\mathrm{j}$ level-2 units (community). Each community in the sample may have different average neonatal deaths $\left(\beta_{0 j}\right)$. We are allowing the intercept to vary across level-2 units. $\mu_{0 j}$, is the error or un-modeled variability for unit $j$ or $j^{\text {th }}$ the community. It can be noticed that the Level-1 error variance is not mentioned. Because in HLM with binary outcome variables the variance is completely determined by the mean, hence no separate effort term for level- 1 . The $\tau_{00}$, is the mean value of the level-1 dependent variable when no co-varaites is used in the model. The $\sigma^{2}$ is the variance estimate due to level-1 predictors which is constant in GLIMMIX when no co-variates are used in the model and the value is $\left(\frac{\pi^{2}}{3}\right)$. 
Table 2. Neonatal deaths as an outcome of community availability of doctor or village attendant/guide or mobile health unit in EAG States.

\begin{tabular}{|c|c|c|c|c|c|}
\hline \multirow{2}{*}{ GLIMIX Estimates } & \multirow{2}{*}{ Estimate } & \multirow{2}{*}{ SE } & \multirow{2}{*}{$\operatorname{Pr}>|t|$} & \multicolumn{2}{|c|}{ Confidence Interval } \\
\hline & & & & Lower & Upper \\
\hline \multicolumn{6}{|l|}{ Model 1} \\
\hline \multicolumn{6}{|l|}{ Unconstrained } \\
\hline Intercept & -2.7625 & 0.09 & $<0.0001$ & -2.9497 & -2.5753 \\
\hline \multicolumn{6}{|l|}{ Model 2} \\
\hline \multicolumn{6}{|l|}{ (Random Intercept Fixed Slope Covariates at Level 1) } \\
\hline \multicolumn{6}{|l|}{ Level 1 predictor } \\
\hline Intercept & -2.1994 & 0.15 & $<0.0001$ & -2.5041 & -1.8948 \\
\hline TT inj & -0.7198 & 0.16 & $<0.0001$ & -1.0227 & -0.4169 \\
\hline Literacy & -0.3848 & 0.17 & 0.0196 & -0.7080 & -0.0617 \\
\hline Marriage to First IBI & 0.1643 & 0.15 & 0.2855 & -0.1373 & 0.4658 \\
\hline \multicolumn{6}{|l|}{ Model 3} \\
\hline \multicolumn{6}{|c|}{ (Random Intercept Fixed Slope Outcome dependent on Level 2 Covariate (connectivity) } \\
\hline \multicolumn{6}{|l|}{ Level 1 predictor } \\
\hline Intercept & -2.1151 & 0.32 & $<0.0001$ & -2.7721 & -1.4582 \\
\hline TT inj & -0.7238 & 0.16 & $<0.0001$ & -1.0281 & -0.4195 \\
\hline Literacy & -0.3934 & 0.17 & 0.0173 & -0.7174 & -0.0694 \\
\hline Marriage to First IBI & 0.1647 & 0.15 & 0.2846 & -0.1370 & 0.4663 \\
\hline \multicolumn{6}{|l|}{ Level 2 predictor } \\
\hline $\begin{array}{l}\text { Community availability of doctor or village } \\
\text { attendant/guide or mobile health unit (hwmu) }\end{array}$ & -0.1023 & 0.32 & 0.7544 & -0.7605 & 0.5560 \\
\hline
\end{tabular}

Level 1

$$
\eta_{i j}=\beta_{0 j}
$$

Level 2

$$
\beta_{0 j}=\gamma_{00}+\mu_{0 j} \quad \text { where } \mu_{0 j} N\left(0, \tau_{00}\right)
$$

Combined

$$
\eta_{i j}=\gamma_{00}+\mu_{0 j}
$$

From the above model 1 which is intercept only model we get the value of ICC as

$$
\text { ICC }=\frac{\tau_{00}}{\tau_{00}+\sigma^{2}}=\frac{2.7625}{2.7625+\left(\frac{\pi^{2}}{3}\right)}=\frac{2.7625}{2.7625+3.289}=0.4565
$$

From the Equation (2) we get the value of ICC as 0.4565 or the 46 percent of the total variance in neonatal deaths is due to the between community differences. As a next step in the model building covariates at level 1 (individual level) 
were introduced in the model and the intercept was allowed to vary across the community. For model to converge only those covariates at level were included in the model those that were relatively significant such as mothers literacy $(0=$ illiterate \& $1=$ literate), tetanus toxide injection during pregnancy $(0=$ no \& $1=$ yes) and marriage to first birth interval ( $\mathrm{BI} \leq 33$ months $=0 \&>33$ months $=1)$. The model specification is given by Equation (3) below

Level 1

$$
\eta_{i j}=\beta_{0 j}+\beta_{1 j}\left(\text { literacy }_{i j}\right)+\beta_{2 j}\left(\text { TTinjecion }_{i j}\right)+\beta_{3 j}\left(B I_{i j}\right)
$$

Level 2

$$
\begin{aligned}
& \beta_{0 j}=\gamma_{00}+\mu_{0 j} \text { where } \mu_{0 j} N\left(0, \tau_{00}\right) \\
& \beta_{1 j}=\gamma_{10} \\
& \beta_{2 j}=\gamma_{20} \\
& \beta_{3 j}=\gamma_{30}
\end{aligned}
$$

Combined

$$
\eta_{i j}=\gamma_{00}+\gamma_{10}\left(\text { literacy }_{i j}\right)+\gamma_{20}\left(\text { TTinjection }_{i j}\right)+\gamma_{30}\left(B I_{i j}\right)+\mu_{0 j}
$$

In the model 3 the intercepts are allowed to vary across communities but the slope is fixed. The findings present in Table 2 under model 1 shows the relative importance of the predictor variable at individual level (level 1) in predicting the neonatal deaths. TT injection during pregnancy strongly predicts the neonatal deaths. So it is important to get the pregnant mother vaccinated by TT injection to prevent neonatal deaths. The mother literacy is also an important covariate significant at 5 percent level of significance in explaining neonatal deaths. To study the impact of the presence of private doctor, or a visiting doctor, traditional attendant or village guide and mobile health unit in the community which are level 2 predictors were built into the model to study the impact of presence of either of the one level-2 predictor in the community on neonatal deaths at individual level. It is hypothesized that presence of any of the level-2 indicator will improve the survival chance of neonates. The model specification is given by Equation (4) below

Level 1

$$
\eta_{i j}=\beta_{0 j}+\beta_{1 j}\left(\text { literacy }_{i j}\right)+\beta_{2 j}\left(\text { TTinjection }_{i j}\right)+\beta_{3 j}\left(B I_{i j}\right)
$$

Level 2

$$
\begin{aligned}
& \beta_{0 j}=\gamma_{00}+\gamma_{01}\left(h_{w m u_{j}}\right)+\mu_{0 j} \quad \text { where } \mu_{0 j} N\left(0, \tau_{00}\right) \\
& \beta_{1 j}=\gamma_{10} \\
& \beta_{2 j}=\gamma_{20} \\
& \beta_{3 j}=\gamma_{30}
\end{aligned}
$$

Combined

$\eta_{i j}=\gamma_{00}+\gamma_{10}\left(\right.$ literacy $\left._{i j}\right)+\gamma_{20}\left(\right.$ TTinjection $\left._{i j}\right)+\gamma_{30}\left(B I_{i j}\right)+\gamma_{01}\left(h_{w m u}\right)+\mu_{0 j}$

Here ' $h w m u$ ' in Equation (4) is a combined variable at level-2 created from 
the responses of five different set of covariates at level-2 listed in Tabe- 1 . The $h w m u$ is a dichotomous predictor variable at level-2. The main effect of the predictors at level-1 after the introduction of the level-2 predictor does not change. Mothers literacy and the TT injection during pregnancy were still the important predictors explaining the variations in the neonatal mortality at individual level. The communities were either private doctor, or a visiting doctor or a traditional health attendant, or a village guide, or a mobile health unit was present had less chance of neonatal deaths compared to those villages/communities where the private doctor, or a visiting doctor or a traditional health attendant, or a village guide, or a mobile health unit were not present. The risk of neonatal death in such communities were $[\exp (-0.1093)=0.9028] 10$ percent less compared to the communities where the private doctor, or a visiting doctor or a traditional health attendant, or a village guide, or a mobile health unit were not present. [exponential of the effect $(-0.1093)$ due to community variable is taken to get odds ratio estimates] However, this is not statistically significant. So it is not definite to conclude that the presence of community doctor/health worker or mobile unit improves individual neonatal survival chances.

\section{Conclusion}

At individual level mother's literacy is the most important variable as the risk of neonatal deaths among illiterate mothers is high compared to literate mothers. Government intervention of providing tetanus toxide injection to mothers during pregnancy is another statistically significant variable. Those mothers who received no TT injections during pregnancy have much higher risk of neonatal deaths than those who received any number of TT injections during pregnancy. The village or the community level availability of either the private doctor or a visiting doctor or a village health guide or traditional attendant or a mobile van reduces the neonatal deaths by 10 percent however it's statistically not significant. As 40 percent of the neonatal deaths occur on day one and given the fact that high proportion of deliveries in EAG states still occur at home, it is imperative that the deliveries that happen at home happen under the supervision of SBA trained ANM. The success of HBNC program initiated in 2011/2012 largely depends on quality training provided to ASHAs in identifying danger signs among neonates and guiding the family members to get speedy referral and admission into state of art Sick New Born Care Units set up at district hospitals. Future demographic surveys in India should capture more and more community level indicators in order to assess the success of governmental interventions within the communities. Government's community based health intervention programs are largely made after the launch of National Health Mission programs in 2005 after the NFHS-2 data was collected and this being the limitation of the study.

\section{References}

[1] Planning Commission (2007) Eleventh Five Year Plan (2007-12). Planning Com- 
mission, Yojana Bhavan, Government of India, New Delhi.

[2] National Rural Health Mission (2011) Home Based Newborn Care. Operational Guidelines. Ministry of Health and Family Welfare, Nirman Bhavan, Government of India, New Delhi.

[3] Bang, A.T., et al. (1999) Effect of Home-Based Neonatal Care and Management of Sepsis on Neonatal Mortality: Field Trial in Rural India. Lancet, 354, 1955-1961. https://doi.org/10.1016/S0140-6736(99)03046-9

[4] Gogia, S. and Sachdev, H.S. (2010) Home Visits by Community Health Workers to Prevent Neonatal Deaths in Developing Countries: A Systematic Review. Bulletin of the World Health Organization, 88, 658-666. https://doi.org/10.2471/BLT.09.069369

[5] Gogia, S. and Sachdev, H.S. (2016) Home-Based Neonatal Care by Community Health Workers for Preventing Mortality in Neonates in Low- and Middle-Income Countries: A Systematic Review. Journal of Perinatology, 36, S55-S73. https://doi.org/10.1038/jp.2016.33

[6] USAID (1999) Reducing Perinatal and Neonatal Mortality. Child Health Research Project Special Report. Report of a Meeting Baltimore, Maryland, 10-12 May 1999, Volume 3, Number 1.

[7] Samira, A., Qazi,S., Wolfheim, C., Oyegoke A. and Bahl, R. (2014) Community Health Workers: A Crucial Role in Newborn Health Care and Survival. Journal of Global Health, 4.

[8] Darmstadt, G.L., et al. (2009) Validation of Community Health Workers' Assessment of Neonatal Illness in Rural Bangladesh. Bulletin of the World Health Organization, 87, 12-19. https://doi.org/10.2471/BLT.07.050666

[9] Devasenapathy, N., et al. (2017) Association of Antenatal Care and Place of Delivery with Newborn Care Practices: Evidence from a Cross-Sectional Survey in Rural Uttar Pradesh, India. Journal of Health, Population, and Nutrition, 36, 30J. https://doi.org/10.1186/s41043-017-0107-z

[10] Wallin, L. (2011) Implementing Knowledge into Practice for Improved Neonatal Survival; a Cluster-Randomised, Community-Based Trial in Quang Ninh Province, Vietnam. BMC Health Services Research, 11, 239. https://doi.org/10.1186/1472-6963-11-239

[11] Howe, L.D., et al. (2011) Developing a Community-Based Neonatal Care Intervention: A Health Facility Assessment to Inform Intervention Design. Paediatric and Perinatal Epidemiology, 25, 192-200. https://doi.org/10.1111/j.1365-3016.2010.01178.x

[12] Roy, S.S., et al. (2013) Improved Neonatal Survival after Participatory Learning and Action with Women's Groups: A Prospective Study in Rural Eastern India. Bulletin of the World Health Organization, 91, 426-433. https://doi.org/10.2471/BLT.12.105171

[13] Kumar, V., et al. (2009) Neonatal Hypothermia in Low Resource Settings: A Review. Journal of Perinatology, 29, 401-412. https://doi.org/10.1038/jp.2008.233

[14] Li, C., et al. (2015) Predictors for Neonatal Death in the Rural Areas of Shaanxi Province of Northwestern China: A Cross-Sectional Study. BMC Public Health, 15, 387. https://doi.org/10.1186/s12889-015-1738-x

[15] International Institute for Population Sciences (IIPS) and ORC Macro International (2000) National Family Health Survey (NFHS-2), 1998-99, Mumbai India. 